\title{
Tension-type headache, its relation to stress, and how to relieve it by cryotherapy among academic students
}

\author{
Mona Hassan ${ }^{1 *}$ and Tarek Asaad ${ }^{2}$
}

\begin{abstract}
Background: Tension-type headache and stress are common students' problems suffering. Alternative and complementary medicine, as cryotherapy, is effective for relieving physical and psychological pain; using ice compresses by placing it at the back of the neck, leads to relief of tension and anxiety, and gives feeling of relaxation and full of energy for doing daily life activities. The findings from this study will provide the basis for the formulation of future research questions that can explore the effect of cryotherapy for treatment of many psychological problems, specifically, researches that consider the role of cryotherapy for treatment of physical and psychological problems.

Aim of the study: This study aimed to assess tension-type headache, its relation to stress, and how to relieve it by cryotherapy, among academic students.

Results: Results revealed that there is an association between stress and tension-type headache, as the level of stress increased, the occurrence of tension-type headache increased.

Conclusion: Academic students experience stress appearing as physical and psychological symptoms that affect their daily life activities. There is a significant relationship between level of stress and $T H$, with diurnal pattern, location, severity, and duration of TTH. After applying cryotherapy (ice compresses) in relieving TTH, students feel analgesia, relaxation, increased effort, and alertness, added to that decreased mental tension and recurrence of headache to a minimum level.
\end{abstract}

Keywords: Tension-type headache, Stress, Cryotherapy, Academic students

\section{Background}

Tension-type headache (TTH) is one of the most frequently reported types of primary headache among adolescents. It is also one of the most neglected headache types, with prevalence of $\sim 15-20 \%$ in population-based studies. Chronic stress, which results from the prolonged imbalance between situational requirements and the individual's coping resources, has been repeatedly found to be related with headaches in adolescents. TTH is more

\footnotetext{
* Correspondence: dr.mona.hassan@nursing.asu.edu.eg

${ }^{1}$ Faculty of Nursing, Ain Shams University, Cairo, Egypt

Full list of author information is available at the end of the article
}

frequent in women than in men, with five women experiencing TTH for every four men $[1,2]$.

TTH was previously called muscle contraction headache. Its name indicates the role of stress and mental or emotional conflict in triggering the pain and contracting muscles in the neck, face, scalp, and jaw. TTHs may also be caused by jaw clenching, intense work, missed meals, depression, anxiety, or too little sleep. The pain is usually mild to moderate and feels as if constant pressure is being applied to the front of the face or to the head or neck. It also may feel as if a belt is being tightened around the head. Most often the pain is felt on both sides of the head [3]. A study was done in Assiut district, Egypt, throughout 1 year (2009), which included 4700 
individuals (male $=49.91 \%$; females $=50.09 \%$ ). Headache was reported in $35.49 \%$ of the individuals. Of them, $87.65 \%(n=1462)$ had primary headache, and of them, 43.78\% ( $n=640)$ had TTH. Female-to-male ratio was 1.8:1. Nearly $59.22 / 32.66 \%$ had moderate/mild headache attacks. Anxiety (27.3\%), depression (23.8\%), and hypertension $(20.5 \%)$ were the common comorbid conditions associated with TTH. It also found that $27.7 \%$ was the common reported condition in the families of individuals with TTH [4].

Students can potentially experience different types of stress that can affect their mental and social health and their academic achievement. Stress is one of the main aspects of our modern life, resulting from the rapid changes in human life. Therefore, this age is called the age of stress. Students exposed to academic stress, resulting from academic tests, home works, and other school requirements, which may exceed their abilities to cope with such stressors. A study on students also indicated that, examinations, fear of falling, shortage in clinical time, decrease in self-esteem, and prompt reduction in time spent in recreational activity have been associated with higher stress levels [5]. Associations with exposure to stressors in adolescents have been reported with TTH. Treatment of frequent TTH is often difficult. TTH is classified into three subtypes according to headache frequency: infrequent episodic TTH (1 day of headache per month), frequent episodic TTH (1-14 days of headache per month), and chronic TTH (15 days per month). It is characterized by a mild-to-moderate headache intensity, a pain that is described as "pressing" and "tightening" and can occur with differing frequencies and durations [1, 2, 6-8].

By definition, this headache involves pain that is not localized, not throbbing, not aggravated by activity, and not severe. There is no significant nausea or vomiting, and photophobia and phonophobia cannot both be present [7]. The peripheral factor pericranial tenderness, which is found inpatients having TTH, seems to be an important clinical issue, but only limited evidence to support this theory has been found. Some studies suggest sensitization of peripheral nociceptors and increased electromyographic activity in trigger points to play a role. Growing evidence now supports that central factors are of greater significance, especially sensitization of neurons at spinal and supraspinal levels as well as decreased inhibition of nociceptive signals leading to an increased sensitivity to pain and thereby causing headaches $[8,9]$.

Cryotherapy is defined as the therapeutic application of any substance to the body that removes heat from the body, resulting in decreased tissue temperature. The pathophysiologic effects of cryotherapy decrease tissue blood flow by causing vasoconstriction, thereby reducing tissue metabolism, oxygen utilization, inflammation, and muscle spasm. Cryotherapy induces effects both locally (at the site of application) and at the level of the spinal cord by neurologic and vascular mechanisms. Topical cold treatment decreases the temperature of the skin and underlying tissues to a depth of $2-4 \mathrm{~cm}$, decreasing the activation threshold of tissue nociceptors and the conduction velocity of pain nerve signals. These results in a local anesthetic effect called cold-induced neuropraxia. Current research shows that cryotherapy decreases tissue blood flow and cell metabolism [10].

At the end of the 1970s, Professor Toshiro Yamauchi constructed the first cryogenic chamber and successfully used cryotherapy to treat rheumatism. The whole-body cryotherapy (WBCT) results in analgesic, antiswelling, and hormone, immune, and circulatory system reactions. It neither affects the heart rate, arterial blood pressure, or the value of the left ventricle fractional shortening index and its ejection nor does it cause arrhythmias and ischemic changes to the heart, and is a safe treatment option if the time of exposure is strictly controlled. It activates the body's system of temperature regulation and hormonal response and also increases body metabolism and the concentration of adrenaline, nor adrenaline, adrenocorticotropic hormone, cortisone, pro-opiomelanocortin and $\beta$ endorphins in blood plasma, as well as male testosterone levels. Pro-opiomelanocortin is the source of several important biologically active substances such as adrenocorticotropic hormone in the anterior pituitary gland and $\alpha$-melanocytestimulating hormones and $\beta$-endorphin in the intermediate lobe. A-melanocyte-stimulating hormone has a role in the regulation of appetite. One of the neurobiological hypotheses of depression is based largely on the dysregulation of the hypothalamic-pituitary-adrenal axis. Brain opioid peptide systems are known to play an important role in motivation, emotion, attachment behavior, the response to stress and pain, and the control of food intake. The positive effects of WBCT in treating both external and internal pain are owing to the activation of the endogenic opioid system and "pain control system." It is possible that such a multi-system reaction could play a role in the treatment of mental disorders. The WBCT is successfully used in clinical work in several countries; however, very limited data are available [11].

The application of cold at repeated intervals leads to an analgesic effect on the parts of the body treated. It has been demonstrated that nerve conduction decreases constantly with a decrease in temperature until conduction within the nerve fibers ceases completely. The myelinated fibers are the first ones to be affected [12]. This slowing of the conductivity of the peripheral nerve fibers is found when the temperature drops to below $80.6^{\circ} \mathrm{F}$ [13]. Other mechanisms are also involved: cold has a specific "anti-irritant" function that protects from pain stimulus [14, 15]. Cold can also remove the causes of pain by reducing muscle spasm of the traumatized area, 
thus reducing the effects of ischemia secondary to the trauma [16].

The physiology of vascular response to cold is complex. Six factors or mechanisms can account for the complexity of the vascular response, which include neuron activity, mechanical receptors, contractile elements of the smooth muscle, platelet activity, the endothelial mechanisms, and rheological factors [17]. Several studies have shown a decrease in peripheral blood flow caused by different methods of application of cold $[18,19]$. There as on sput forward to explain this decrease in blood flow are vasoconstriction caused by the sympathetic nervous system reflex and the affinity caused by the cold of the post-junctional $\alpha$ 2 receptors of the vessel walls [20].

The result of the two factors referred to above is a reduction in the activity of the nor adrenaline enzyme antimetabolites, an increase in blood viscosity, and the activation of the platelet aggregates that release $5 \mathrm{HT}$ and thromboxane A2, causing a high degree of disability. Treatment of frequent TTH is often difficult. TTH is classified into three subtypes according to headache frequency: in frequent episodic TTH (1 day of headache per month), frequent episodic TTH (1-14days of headache per month), and chronic TTH (15 days per month). It is characterized by a mild-to-moderate headache intensity, a pain that is described as "pressing" and "tightening" and can occur with differing frequencies and durations.

\section{Significance of the study}

TTH and stress are common problems the students experience. Alternative and complementary medicine, like cryotherapy, is effective for relieving physical and psychological pain. Use of ice compression by placing it at the back of the neck leads to relief tension and anxiety, and gives feeling of relaxation and full of energy for doing daily life activities. The effects occur like antidepressant drugs. It also decreases recurrence feeling of TTH. The significance of using it comes from the fact that this experience needs no money, no effort, little time, and effective safe alternative therapy for mental tension and TTH for academic students and other people who are suffering from mental tension and tension headache. The results from this study will provide the basis for the formulation of future research questions that can explore the effects of cryotherapy for the treatment of many psychological and physical problems, and more specifically, research studies that will consider the role of cryotherapy for the treatment of physical and psychological problems.

\section{Aim}

This study aimed to assess the relation between stress and TTH among academic students, as well as the role of cryotherapy.

\section{Research question}

What is the relation between stress and TTH? What is the effect of cryotherapy on the TTH?

\section{Research hypothesis}

TTH is associated with stress, and cryotherapy (ice compression) will relieve it.

\section{Methods}

The methodology used in carrying out the study is described under four designs, namely, technical, operational, administrative, and statistical designs. The technical design includes the research design, study setting, sample, and tools of data collection.

\section{Research design}

\section{Mixed-methods study}

This study was designed as a mixed-method study. It involved a sequential mixed-method approach, in which both quantitative data collection and analysis techniques were chronologically undertaken [21, 22]. The study began with a quantitative study and was followed by a qualitative one. Finally, a mixed-method analysis was undertaken for this study, in order to answering the research question.

\section{Study setting}

The present study was carried out at the Faculty of Nursing, Ain Shams University.

\section{Participants}

A convenient sample of 50 academic students was recruited.

\section{Inclusion criteria}

The study included students having TTH recurrence and willing to participate in the study.

\section{Tools of data collection}

Three tools were used to collect data for this study.

Tool I: A structured interview sheet was used for the sociodemographic data. It included six items that elicit sociodemographic characteristics of students under study, such as age, level of education, marital status, residence, and income.

Tool II: This was a stress-based scale used to assess the effect of stress on physical and psychological wellbeing, which was adopted from Abdullah et al. [23].

Tool III: This was a TTH questionnaire adapted from Mahmoud et al. [4].

\section{Operational design}

The operational design for this study includes preparatory phase, pilot study, fieldwork, ethical considerations, and limitations of the study. 


\section{Preparation phase}

This phase deals with the preparation of the study design; data collection tool was adapted by the researcher. TTH questionnaire was primarily developed in English, which needed to be translated into Arabic. Reviewing literature studies and other available resources related to $\mathrm{TTH}$, stress, among academic students, and role of cryotherapy to relieve tension-type headache, for the preparations of data collection tools.

\section{Content validity and reliability of the tools}

Tool II was tested for its content validity and reliability by Abdullah et al. [23]. The tools were tested for their content validity by a jury of thirteen experts in the field of psychology, such as counseling psychology, education, curriculum, and teaching, who ascertained their validity and relevance. The $\alpha$ Chronbach test was used to measure the internal consistency (reliability of the used tool). Tool III: tensiontype headache-based questionnaire was tested for its content validity and reliability by Mahmoud et al. [4].

\section{Pilot study}

A pilot study was carried out before starting the data collection phase. It included ten students. It was conducted to evaluate the simplicity, practicability, legibility, understandability, feasibility, validity, and reliability of the tools, and to assess stress and TTH. No modifications were done for tools s of data collection.

\section{Fieldwork}

Fieldwork of the current study was divided into two stages:

Stage I: It started by reading and exploring related information in scientific magazines and preparing tools of data collection. Then, it dealt with formulating clear and evidence-based scientific data and ideas about cryotherapy and consulting professor of neuropsychiatry about the research idea. This stage takes about 2 years. Then, the dean of the faculty and subjects of the study were informed about the purpose of the study. After that, oral consent was taken, from subjects of the study, after informing them about their right to participate in the study and the information used will be for the sole purpose of the study. The study was conducted on an individual and group basis. Each student can be interviewed individually or with group according to students' circumstances. Each interview lasted for $15-30 \mathrm{~min}, 3$ days per week. The researcher asked the subjects regarding the needed information and then data filled in the two questionnaires (TTH and stress). After that, instructional guidelines about cryotherapy had been given by focused group discussion. The process of data collection took a period of 1 month from November 2015 to December 2015.
Stage II: Instructional guidelines about cryotherapy (ice compression) were introduced for a group of six students as follows:

The subjects of the study were informed about the therapeutic use of locally applied coolants at the back of the neck and its effect in reducing TTH. Conduction occurs when a cool ice compress that applied to the skin at the back of the neck. Cryotherapy has historically been used to provide pain relief. Cryotherapy may additionally be used to elevate the pain threshold. As cooling decreases tissue temperatures, the sensory nerves in the skin are provoked to fire continuously until physiologically exhausted. Usually this causes the participant to predictably experience a sequence of sensations including aching, burning, and finally numbness. Numbness or temporary local anesthesia occurs as the sensory nerves are exhausted. Deeper nerves (below the epidermis) may also be affected by cooling. Muscle cooling has been shown to affect the afferent nerves. This occurs in the muscle after $10 \mathrm{~min}$ of cooling with an ice pack. All nerve fibers are generally affected by cooling. Additionally, cooling has been shown to affect the various vascular structures at all levels to the extent of causing an initial reflex vasoconstriction to occur. Vasoconstriction has been shown to reduce blood flow in tissues cooled to $18^{\circ} \mathrm{C}$. As cooling continues, vasodilatation occurs in a physiological attempt to increase blood flow and thereby prevent tissue damage. This phenomenon is called the hunting reaction.

Cryotherapy is most commonly applied as ice packs, which may be created by putting ice in a plastic bag or by freezing a moistened hydrocollator. A damp towel should be frozen. The towel is then placed over the treatment site for $10-20 \mathrm{~min}$ or until sensory analgesia (temporary local anesthesia) of the skin is produced. This stage took about 1 month, with six sessions, from December 2015 to January 2016. After discussing these instructional guidelines about cryotherapy (ice compresses), the students were followed up and asked frequently about the effect of ice compression on relieving TTH. The students' responses were satisfactory, to a large extent. They stated that TTH and mental tension had been relieved to a very little degree.

Research has shown that during ice compression application, a decline in fast-twitch muscle fiber tension occurs, resulting in a more significant recruitment of slow-twitch muscle fibers, thereby increasing muscle endurance. Because vasoconstriction leads to a decrease in metabolic rate, inflammation, and pain, cryotherapy is usually applied for 20-30min for maximum cooling of both superficial and deep tissues. The cold agent should be applied directly to the skin for optimal therapeutic effects.

\section{Ethical consideration}

The researcher obtained an approval to conduct the research study and received official permission from the 
authority of Faculty of Nursing, Ain Shams University. After obtaining official requirements for carrying out this study, the subjects of the study were informed about the aim and nature of the study, their right to participate in the study, and their right to withdraw at any time without giving any reason and provided reassurance about confidentiality of their information and that data collected will be used only for the purpose of the research.

\section{Limitation of the study}

On proceeding the subjects of the study regarding applying ice compresses at the back of the neck in the early morning, some faced difficulties such as follows: the study was conducted in winter, it was too cold to apply the ice compresses; some stated that they reside in a university hotel and there is no availability of ice compress as in their home; others stated that they work in nightshift, which means they are not at home; and others stated that they forgot to place ice compresses when getting up early in the morning. Only six students followed the instructional guidelines about cryotherapy and continued applying ice compresses.

\section{Administrative design}

An official letter was addressed to the dean of faculty of nursing, requesting her cooperation and permission to conduct the study. After explanation of the study objectives, the researcher obtained the written permission. Complete confidentiality of any obtained information was ensured.

\section{Statistical design}

\section{Data analysis}

Data entry and statistical analysis were done using SPSS statistical software package. IBM Corp. Released 2012. IBM SPSS Statistics for Windows, Version 21.0. Armonk, NY: IBM Corp. quantitative continuous data were compared. Qualitative categorical variables were compared using $X^{2}$ test. Statistical significance was considered at $\mathrm{P}$ value of less than 0.05 .

The focus group is the qualitative part.

\section{Design and ethics consideration}

The study involved a descriptive qualitative study. It aimed to seek how cryotherapy can relieve TTH. Data were collected using semi-structured interviews with six academic students in the faculty of nursing and four academic staff at work.

An interview guideline was developed with three main questions subdivided to many questions as follows:

(1) What are symptoms associated with TTH? (a) Times of recurrence? (b) Characteristics of tension feeling?

(c) Feeling of depressive symptoms?

(d) Anxiety symptoms?

(e) Level of performance of daily activities?

(f) Mood changes?

(g) Sleep quality?

(h) Appetite?

(2) What is the effect of ice compresses on TTH?
(a) Do ice compressions relieve TTH?
(b) The recurrence of headache
(c) The intensity of headache
(d) Mental tension after ice compresses
(e) Stress feeling

(3) Did you observe any physical problems after using ice compresses?

\section{Participants}

The participants were six students, who had TTH and mental tension. They were recruited by a purposive sampling. This sampling method was selected because the study aimed to obtain information from the students with a greater breadth and depth of knowledge regarding tension headache and mental tension.

\section{Data collection}

Data were collected using semi-structured interviews among the recruited students. Before starting of each interview, students were informed about the study, such as the aim of study. In addition, permission to write the interview was sought from each participant. All interviews were conducted in the same pattern according to an interview guideline. Each interview lasted $\sim 30 \mathrm{~min}$. To ensure the consistency of interview, no more than five interviews per day were conducted.

\section{Data analysis}

There were two main processes for data analysis: (a) data preparation and (b) data analysis. The process of data preparation involved transcription and translation. Interview data were transcribed from spoken words into textual data by the researcher. After that, transcriptions were translated into English by the researcher.

Textual data from the interviews were manually analyzed by using thematic analysis technique, which is a method for identifying, analyzing, and reporting themes and concepts with qualitative data [24].

Data were analyzed using the six steps of thematic analysis suggested by Braun et al. [24],

which included the following: (a) familiarizing with the data, (b) generating initial codes, (c) searching for themes, (d) reviewing themes, (e) defining themes, and (f) producing the report.

Qualitative findings were used to examine the effect of cryotherapy on relief of TTH. 


\section{Mixed-methods analysis}

As mixed-methods designs, findings from both the qualitative and quantitative studies were integrated at the final stage. The findings of both studies were combined in two ways. First, as the findings of the crosssectional study were reported in a numeric form, these may be too abstract to explain the detail of cryotherapy on relief of TTH among academic students.

Consequently, the interpretation of the findings using two different research approaches offered a breadth and depth of understanding about the status of TTH after proceeding cryotherapy (ice compresses).

\section{Results}

Table 1 describes the sociodemographic data of the study sample. It shows that the entire study group (100\%) represented females, and they were between the ages of 20 and 25 years. Moreover, $80 \%$ of them live outside Cairo, are single, and have satisfactory income.

Psychological and cognitive symptoms of stress are shown in Table 2 . It is clear that $76.9 \%$ of study sample feel the importance of doing most of things as soon as possible to a large degree, whereas $75.0 \%$ of them were not satisfied about what they had achieved in their life Added to that, $90.4 \%$ of students did many things at the same time, while $80.8 \%$ of them felt disturbed when things were not done completely.

As illustrated in Table 3, regarding physical symptoms of stress, it appears that $46.2 \%$ of students find it difficult to get up early in the morning. Moreover, $63.5 \%$ of the students experience neck pain to a large degree, whereas

Table 1 Sociodemographic characteristics of academic students $(n=50)$

\begin{tabular}{lll}
\hline Sociodemographic & Number & Percentage (\%) \\
\hline Age & - & - \\
$>20$ & 50 & 100 \\
$20-25$ & - & - \\
Sex & 50 & 100 \\
Male & & \\
Female & 10 & 20 \\
Residence & 40 & 80 \\
Inside Cairo & & \\
Outside Cairo & 7 & 14 \\
Engagement & 3 & 6 \\
Engaged & 40 & 80 \\
Married & & 80 \\
Single & 40 & 20 \\
Income & 10 & \\
Satisfied & & \\
Not satisfied & &
\end{tabular}

$57.7 \%$ of them sometimes experience persistent headache leading to mood changes.

Table 4 illustrates the TTH scale, which reveals that $48 \%$ had a TTH that was tight and pressing, 54\% had dull aching, and $86 \%$ felt heaviness. However, the diurnal pattern of TTH was as follows: $38 \%$ had headache that worsens at the end of the day and $48 \%$ of them have no diurnal variation. The prodromal symptoms included $26 \%$ had depressed mood and 90\% felt fatigued, whereas postdrome symptoms represent $38 \%$ for depression, and $94 \%$ for exhaustion. Regarding location of the headache, $32 \%$ of them had it in the temporal and occipital area. It is also found that $78 \%$ of study sample, their headache is infrequent, and $76 \%$ of study sample, their headache moderate in severity, with duration from 2 to $4 \mathrm{~h}$ in $36 \%$ of the study sample.

The relationship between level of stress and TTH is shown in Table 5, which shows that there is a significant relationship between level of stress with diurnal pattern, location, severity, and duration, demonstrated as 0.01 , $0.001,0.013$, and 0.001 respectively.

\section{Results about qualitative part Qualitative findings}

(1) What are the symptoms associated with TTH that you are suffering from?

The following statements followed by its answers:

(a) Times of recurrence

We cannot calculate accurately, but it frequently happens weekly.

(b) Characteristic of tension feeling

Tension-like belt around my head and my head is heavy.

(c) Feeling of depressive symptoms?

Disturbed appetite, disturbed sleep, and doing daily living activity with little effort.

(d) Anxiety symptoms

Feeling like loaded with a lot of things, and need to do many things at the same time.

(e) Level of performance of daily activities

We are not satisfied about our achievements regarding daily activities.

(f) Mood changes

From time to time, between nervousness and calmness (g) Sleep quality

Getting up with difficulty, disturbed sleep, between many and little hours

(h) Appetite

Disturbed appetite, and sometimes we have no time to eat.

(2) What is the effect of ice compresses on TTH? 
Table 2 Psychological symptoms of stress among academic students $(n=50)$

\begin{tabular}{|c|c|c|c|c|c|c|c|c|c|c|}
\hline \multirow[t]{2}{*}{ Psychological symptoms } & \multicolumn{2}{|c|}{$\begin{array}{l}\text { Very large } \\
\text { degree }\end{array}$} & \multicolumn{2}{|c|}{$\begin{array}{l}\text { Large } \\
\text { degree }\end{array}$} & \multicolumn{2}{|c|}{$\begin{array}{l}\text { Moderate } \\
\text { degree }\end{array}$} & \multicolumn{2}{|c|}{$\begin{array}{l}\text { Little } \\
\text { degree }\end{array}$} & \multicolumn{2}{|c|}{$\begin{array}{l}\text { Very little } \\
\text { degree }\end{array}$} \\
\hline & $\bar{n}$ & $\%$ & $\bar{n}$ & $\%$ & $\bar{n}$ & $\%$ & $\bar{n}$ & $\%$ & $\bar{n}$ & $\%$ \\
\hline I feel importance of doing most of things as soon as possible. & 9 & 17.3 & 40 & 76.9 & 1 & 1.9 & 2 & 3.8 & 0 & 0 \\
\hline It is difficult to feel at ease even for few hours. & 10 & 19.2 & 32 & 61.5 & 4 & 7.7 & 2 & 3.8 & 4 & 7.7 \\
\hline I'm not satisfied about what I achieved in my life. & 7 & 13.5 & 39 & 75.0 & 3 & 5.8 & 1 & 1.9 & 2 & 3.8 \\
\hline I need to do many things at the same time. & 3 & 5.8 & 47 & 90.4 & 2 & 3.8 & 0 & 0 & 0 & 0 \\
\hline I feel disturbed when things did not made perfectly. & 8 & 15.4 & 42 & 80.8 & 2 & 3.8 & 0 & 0 & 0 & 0 \\
\hline 11 work under pressure to end most of work. & 20 & 38.5 & 28 & 53.8 & 4 & 7.7 & 0 & 0 & 0 & 0 \\
\hline $\begin{array}{l}\text { I'm always mentally preoccupied with missions while talking } \\
\text { with others. }\end{array}$ & 26 & 50 & 19 & 36.5 & 5 & 9.6 & 2 & 3.8 & 0 & 0 \\
\hline I feel proud while working better under pressure. & 3 & 5.8 & 11 & 21.2 & 25 & 48.1 & 11 & 21.2 & 2 & 3.8 \\
\hline I have many states of amnesia. & 21 & 40.4 & 24 & 46.2 & 7 & 13.5 & 0 & 0 & 0 & 0 \\
\hline I'm decline to rapid speaking. & 19 & 36.5 & 17 & 32.7 & 11 & 21.2 & 5 & 9.6 & 0 & 0 \\
\hline
\end{tabular}

(a) Do ice compresses relieve TTH?

There is a clear difference before and after using ice compresses in relieving TTH. Feeling like analgesics, relaxation, increased power and alertness, some of them feel increased appetite, others feel decreased appetite, and increased desire to sleep for someone. The period between recurrences increased. No mental tension or hard tidiness around head like before.

(b) The recurrence of headache decreased to a large extent.

(c) The intensity of headache

Low intensity to very little degree, and some of them advised their family to use ice compresses to relieve their TTH.

(d) Mental tension after ice compresses

Decreased tidiness, tension, and anxiety to a minimum level

(e) Stress feeling
It is a good method of stress management.

(3) Did you observe any physical problems after using ice compresses?

Not at all, except for someone observed decreased appetite, whereas others observed increased appetite, and gives an ability to spend more time studying than usual.

\section{Discussion}

Students can potentially experience different types of stress that can affect their mental and social health and their academic achievement. Stress is one of the main aspects of our modern life, resulting from the rapid changes in human life. Therefore, this age is called the age of stress [5]. Associations with exposure to stressors in adolescents have been reported with TTH. TTH is found to be associated with stress and mental tension $[1-4,5-8]$. Cold treatment (cryotherapy) which is a simple and cheap treatment method has an important place in nondrug therapies for pain management [25]. Topical cold treatment decreases the temperature of the skin and underlying tissues to a depth of $2-4 \mathrm{~cm}$, decreasing

Table 3 Physical symptoms of stress among academic students $(n=50)$

\begin{tabular}{|c|c|c|c|c|c|c|c|c|c|c|}
\hline \multirow[t]{2}{*}{ Physical symptoms } & \multicolumn{2}{|c|}{ Very large degree } & \multicolumn{2}{|c|}{ Large degree } & \multicolumn{2}{|c|}{ Moderate degree } & \multicolumn{2}{|c|}{ Little degree } & \multicolumn{2}{|c|}{ Very little degree } \\
\hline & $n$ & $\%$ & $n$ & $\%$ & $n$ & $\%$ & $n$ & $\%$ & $n$ & $\%$ \\
\hline I'm suffering from overweight. & 1 & 1.9 & 8 & 15.4 & 33 & 63.5 & 10 & 19.2 & 0 & 0 \\
\hline I'm difficult to get up early at morning. & 17 & 32.7 & 24 & 46.2 & 11 & 21.2 & 0 & 0 & 0 & 0 \\
\hline I feel general malaise. & 26 & 50 & 21 & 40.4 & 5 & 9.6 & 0 & 0 & 0 & 0 \\
\hline I feel anxious. & 3 & 5.8 & 4 & 7.7 & 35 & 67.3 & 10 & 19.2 & 0 & 0 \\
\hline I suffer from gastrointestinal discomfort. & 4 & 7.7 & 26 & 50 & 20 & 38.5 & 2 & 3.8 & 0 & 0 \\
\hline I feel with neck pain. & 12 & 23.1 & 33 & 63.5 & 6 & 11.5 & 1 & 1.9 & 0 & 0 \\
\hline Persistent headache makes mood changes. & 0 & 0 & 5 & 9.6 & 30 & 57.7 & 12 & 23.1 & 5 & 9.6 \\
\hline
\end{tabular}


Table 4 Tension-type headache symptoms' scale among academic students ( $n=50)$

\begin{tabular}{|c|c|c|}
\hline Tension-type headache symptoms & $n$ & $\%$ \\
\hline \multicolumn{3}{|l|}{ Character } \\
\hline Burning/boiling & 4 & 8 \\
\hline Tight/pressing & 24 & 48 \\
\hline Dull aching & 27 & 54 \\
\hline Numbness/tingling & 10 & 20 \\
\hline Heaviness & 43 & 86 \\
\hline \multicolumn{3}{|l|}{ Diurnal pattern } \\
\hline Worse at the end of the day & 19 & 38 \\
\hline Worse in the morning & 7 & 14 \\
\hline No diurnal variation & 24 & 48 \\
\hline \multicolumn{3}{|l|}{ Prodromal symptoms } \\
\hline Depressed mode & 13 & 26 \\
\hline Fatigue & 45 & 90 \\
\hline \multicolumn{3}{|l|}{ Location } \\
\hline Vertex & 9 & 18 \\
\hline Temporal and frontal & 0 & 0 \\
\hline Frontal & 12 & 24 \\
\hline Temporal and vertex & 13 & 26 \\
\hline Temporal and occipital & 16 & 32 \\
\hline Whole head & 0 & 0 \\
\hline \multicolumn{3}{|l|}{ Postdrome } \\
\hline Depressed mood & 19 & 38 \\
\hline Exhaustion & 47 & 94 \\
\hline \multicolumn{3}{|l|}{ Frequency } \\
\hline Infrequent & 39 & 78 \\
\hline Frequent & 9 & 18 \\
\hline Chronic & 0 & 0 \\
\hline Chronic daily headache & 2 & 4 \\
\hline \multicolumn{3}{|l|}{ Severity } \\
\hline Mild & 13 & 26 \\
\hline Moderate & 38 & 76 \\
\hline Severe & 0 & 0 \\
\hline \multicolumn{3}{|l|}{ Duration } \\
\hline$<2 \mathrm{~h}$ & 32 & 64 \\
\hline $2-4 h$ & 18 & 36 \\
\hline $4-24 h$ & 0 & 0 \\
\hline $24-72 \mathrm{~h}$ & 0 & 0 \\
\hline Intermittent then persistent & 0 & 0 \\
\hline
\end{tabular}

Answers are not mutually exclusive

the activation threshold of tissue nociceptors and the conduction velocity of pain nerve signals.

This results in a local anesthetic effect called coldinduced neuropraxia. Current research shows that cryotherapy decreases tissue blood flow and cell metabolism
Table 5 Relation between stress and tension-type headache among academic students $(n=50)$

\begin{tabular}{|c|c|c|c|c|c|}
\hline \multirow[t]{2}{*}{ Tension-type headache } & \multicolumn{2}{|c|}{ Level of stress } & \multirow[t]{2}{*}{ Total } & \multirow[t]{2}{*}{ Chi } & \multirow[t]{2}{*}{$P$ value } \\
\hline & High & Moderate & & & \\
\hline \multicolumn{6}{|l|}{ Diurnal pattern } \\
\hline $\begin{array}{l}\text { Worse at the end of the } \\
\text { day }\end{array}$ & 19 & 0 & 19 & 21.065 & 0.01 \\
\hline Worse in the morning & 7 & 0 & 7 & & \\
\hline No diurnal variation & 10 & 14 & 24 & & \\
\hline \multicolumn{6}{|l|}{ Location } \\
\hline Vertex & 9 & 0 & 9 & 41.319 & .001 \\
\hline Frontal & 12 & 0 & 12 & & \\
\hline Temporal and vertex & 13 & 0 & 13 & & \\
\hline Temporal and occipital & 2 & 14 & 16 & & \\
\hline \multicolumn{6}{|l|}{ Frequency } \\
\hline Infrequent & 25 & 14 & 39 & 5.484 & .064 \\
\hline Frequent & 9 & 0 & 9 & & \\
\hline Chronic daily headache & 2 & 0 & 2 & & \\
\hline \multicolumn{6}{|l|}{ Severity } \\
\hline Mild & 12 & 0 & 12 & 6.140 & .013 \\
\hline Moderate & 24 & 14 & 38 & & \\
\hline \multicolumn{6}{|l|}{ Duration } \\
\hline$<2 \mathrm{~h}$ & 32 & 0 & 32 & 34.568 & .001 \\
\hline $2-4 h$ & 4 & 14 & 18 & & \\
\hline \multicolumn{6}{|l|}{ Chronic daily headache } \\
\hline No & 36 & 12 & 48 & 5.357 & .021 \\
\hline Yes & 0 & 2 & 2 & & \\
\hline Total & 36 & 14 & 50 & & \\
\hline
\end{tabular}

[10]. Regarding physical symptoms of stress, in this study, it was found that slightly less than two-thirds (63.5) of the students felt neck pain to a large degree. This result matches with Kjaergaard [8], who found that stress leads to an increased sensitivity to pain and thereby causes headaches. Although more than half (57.7\%) of them had moderate degree of headache, they sometimes experienced persistent headache which led to mood changes. This is in agreement with Soderberg [1] who reported that stress is associated with TTH.

Regarding psychological and cognitive symptoms of stress, it is clear that $76.9 \%$ of study participants feel the importance of doing most of the things as soon as possible to a large degree, whereas $75.0 \%$ of them were not satisfied about what they had achieved in their life. Moreover, $90.4 \%$ of students did many things at the same time, and $80.8 \%$ of them felt disturbed when things were not done perfectly. This is comparable to a study one by Ahmad and Qaisy [5] who reported that students can potentially experience different types of stress that can affect their mental and social health and their 
academic achievement. Stress is one of the main aspects of our modern life, resulting from the rapid changes in human life. Therefore, this age is called the age of stress. Students experience academic stress resulted from academic tests, home works, and other school requirements that may exceed their abilities to cope with them. A study on students also indicated that examinations, fear of falling, shortage in clinical time, decrease in selfesteem, and prompt reduction in time spent in recreational activity have been associated with higher stress levels.

Regarding TTH scale, it is revealed that in less than half of the studied sample, the characteristic of TTH was tight and pressing, and this is in agreement with Bendtsen et al. [6]. Slightly more than half had dull aching headache, and most of them felt heaviness. However, diurnal pattern of TTH was as follows: more than one-third of the studied sample had headache that worsens at the end of the day, and slightly less than half of them have no diurnal variation. The prodromal symptoms included more than onefourth of them having depressed mood, and most of them feeling fatigued, whereas postdrome symptoms represent more than one-third for depression, and most of them feel with exhaustion. Regarding location of the headache, approximately one-third of them had their headache in temporal and occipital area. It is also found that in majority of the study sample, the headache was infrequent, and moderate in severity, with duration from 2 to $4 \mathrm{~h}$ in more than one-third of the study sample. This is in the same line of National Institutes of Health Publication [3] which stated that TTH, previously called muscle contraction headache, is the most common type of headache. Its name indicates the role of stress and mental or emotional conflict in triggering the pain and contracting muscles in the neck, face, scalp, and jaw. TTHs may also be caused by jaw clenching, intense work, missed meals, depression, anxiety, or too little sleep. Sleep apnea may also cause TTHs, especially in the morning. The pain is usually mild to moderate and feels as if constant pressure is being applied to the front of the face or to the head or neck. It also may feel as if a belt is being tightened around the head. Most often the pain is felt on both sides of the head. People who experience TTHs may also feel overly sensitive to light and sound but there is no preheadache aura as with migraine. Typically, TTHs usually disappear once the period of stress or related cause has ended. TTHs affect women slightly more often than men. The headaches usually begin in adolescence and reach peak activity in the 30s. They have not been linked to hormones and do not have a strong hereditary connection. There are two forms of TTH: Episodic TTHs occur between 10 and 15 days per month, with each attack lasting from 30 min to several days. Although the pain is not disabling, the severity of pain typically increases with the frequency of attacks. Chronic tension- type attacks usually occur more than 15 days per month over a 3-month period. The pain, which can be constant over a period of days or months, strikes both sides of the head and is more severe and disabling than episodic headache pain. Chronic tension headaches can cause ore scalps-even combing your hair can be painful. Most individuals will have had some form of episodic TTH before the onset of chronic TTH. Depression and anxiety can cause TTHs. Headaches may appear in the early morning or evening, when conflicts in the office or at home are anticipated. Other causes include physical postures that strain head and neck muscles (such as holding your chin down while reading or holding a phone between your shoulder and ear), degenerative arthritis of the neck, and temporomandibular joint dysfunction (a disorder of the joints between the temporal bone located above the ear and the mandible, or lower jawbone).

Regarding the relationship between level of stress and TTH, there is a statistical significant relationship between level of stress with diurnal pattern, location, severity, and duration of TTH. As in a studies by $[1,2,6]$ about associations with exposure to stressors in adolescents which have been reported with TTH and is cryotherapy (ice compresses) in relieving TTH, students feel analgesia, relaxation, increased effort, and alertness, added to that decreased mental tension and recurrence of headache to a minimum level.

\section{Conclusion}

Academic students experience stress appearing as physical and psychological symptoms that affect their daily life activities. There is a significant relationship between level of stress and TTH, with diurnal pattern, location, severity, and duration of TTH. After applying cryotherapy (ice compresses) in relieving TTH, students feel analgesia, relaxation, increased effort, and alertness, added to that decreased mental tension and recurrence of headache to a minimum level.

\section{Recommendations}

(1). Cryotherapy (ice compresses) is a nonpharmacological therapy for TTH relief.

(2). Ice medicine can be establishing as a new branch of medicine.

(3). Fifteen to 20 min of ice compression at the back of the neck at the beginning of the day is efficient to prevent and relief TTH.

(4). Ice compresses can be added as a new method of stress management.

(5). Ice compression is a rapid and effective method for TTH management.

(6). Ice compression can be used for other types of headache like, aura, migraine, and cluster headache. 
(7). Ice compression is a cheap method of treatment that needs no money, no time, and no effort.

\section{Further researches}

(8). Research is needed regarding the effect of cryotherapy on memory enhancement.

(9). More research is needed about the relation between cryotherapy and reducing obesity.

(10)More research is needed about the relation between cryotherapy and physical immunity.

(11)More research is needed about the relation between cryotherapy and sleep disturbances.

(12)Ice compresses can be used in the management of different psychiatric disorders, like schizophrenia, and bipolar disorders, different anxiety disorders and depression.

(13)More research is needed about the role of ice compression in the relief of physical and psychological pain.

(14)More research is needed about the role of ice compression in the relief of multiple sclerosis.

\section{Abbreviations}

TTH: Tension-type headache; WBCT: Whole body cryotherapy

\section{Acknowledgements}

Appreciation and gratefulness to Professor Salwa Samir, Professor of Medical Surgical Nursing and Dean of Faculty of Nursing-Ain Shams University for her valuable support of this research.

Appreciation and gratefulness to the students at the Faculty of Nursing, Ain Shams University for their cooperation in this work. Thanks to all subjects and field researchers who participated in this research.

\section{Authors' details}

'Associate Professor of Psychiatric/Mental Health Nursing, Faculty of Nursing, Ain Shams University, Egypt, dr.mona.hassan@nursing.asu.edu.eg

${ }^{2}$ Professor of Neuropsychiatry, Faculty of Medicine, Institute of Psychiatry, Ain

Shams University, Egypt, dr.tarekasaad@yahoo.com

\section{Authors' contributions}

All authors participated in all steps of coordination, designing the study, fieldwork, and data collection was by "MH" and collected the relevant information, statistical analysis of the collected data, interpreted the results, and wrote the manuscript. Revised by Professor "TA" who supervised the study. All authors read and approved the final manuscript.

\section{Funding}

Not applicable

\section{Availability of data and materials}

The datasets used and/or analyzed during the current study are available from the corresponding author on reasonable request.

\section{Ethics approval and consent to participate}

Consent had received from the Dean of faculty of Nursing, (Professor: Salwa Samir). A consent was obtained oral from all the participants after the explanation of the procedures and the objectives of the study.

\section{Consent for publication}

No personal data included in the questionnaire.

\section{Competing interests}

The authors have no competing interests.

\section{Author details}

${ }^{1}$ Faculty of Nursing, Ain Shams University, Cairo, Egypt. ${ }^{2}$ Faculty of Medicine, Institute of Psychiatry, Ain Shams University, Cairo, Egypt.

Received: 24 August 2019 Accepted: 27 March 2020

Published online: 22 May 2020

\section{References}

1. Söderberg E. Chronic tension-type headache treatment with acupuncture, physical training and relaxation training. Göteborg, Sweden: Institute of Neuroscience and Physiology. ahlgrenska Academy at University of Gothenburg;2012.

2. Milde A, Blaschek A, Heinen F, Borggrafe I, Koerte I, Straube A et al (2011) Associations between stress and migraine and tension-type headache: results from a school-based study in adolescents from grammar schools in Germany. Cephalalgia 31:774-785

3. National Institutes of Health Publication. (2009): Hope through research. No. 09-158August.

4. Mahmoud R, Hamed SH, Fadel K, Ahmad H, Mohammed A, Khaled O (2014) Epidemiology of tension-type headache (TTH) in Assuit Governorate, Egypt. J NeurolNeurosci 5:2

5. Ahmad M, Qaisy M. Assessingstressamonguniversitystudents. Am Int J Contemp Res 2012;2:

6. Bendtsen L, Evers S, Linde M, Mitsikostas D, Sandrini G, Schoenen J (2010) EFNS guideline on the treatment of tension-type headache - report of an EFNS task force. Eur J Neurol 17:1318-1325

7. Kaniecki RG (2012) Tension-type headache. Continuum (MinneapMinn) 18: 823-834

8. Kjaergaard M. (2012)Vitamin D, depression and headache-results from the Tromso study and from an intervention study with vitamin D. dissertationfor thedegreeofPhilosophiaeDoctorFacultyofHealthSciencesDepartmentof ClinicalMedicine.

9. International Headache Society (2013) Headache classification committee of the International Headache Society (IHS) the international classification of head-ache disorders, 3rd edition (beta version). Cephalalgia 33:629-808

10. Nadler SF, Weingand K, Kruse RJ (2004) The physiologic basis and clinical applications of cryotherapy and thermotherapy for the pain practitioner. Pain Physician 7:395-399

11. Rymaszewska J, Ramsey D (2008) Whole body cryotherapy as novel adjuvant therapy for depression and anxiety. Arch Psychiatry Psychother 2: 49-57

12. Murphy AJ (1959) The physiological effects of cold application. PhysTher Rev 40:112-115

13. Meeusen R, Lievens $P$ (1986) The use of cryotherapy in sports injuries. Sports Med 3:398-414

14. Ernst E, Fialka V (1994) Ice freeze spain? A review of the clinical effectiveness of analgesic cold therapy. J Pain Symptom Manag 9:56-59

15. Scheffler N, Sheitel P, Lipton M (1992) Use of Cryo/Cuff for the control of post- operative pain and edema. J Foot Surg 31:141-148

16. Hocutt JE (1981) Cryotherapy. Am Fam Physician 23:141-4.1

17. Bodelsson M (1990) Vascular effects of cooling, with special reference to human serotonergic, adrenergic and endothelial mechanisms Medicalissertation. Lund University, Lund

18. Barcoft H, Edholm O (1943) The effect of temperature on blood flow and deep temperature in the human forearm. J Physiol 102:5-20

19. Snedeker J, Recine V, MacCartee C (1974) Cryotherapy and the athletic injury. Athletic J 55:16-18

20. Taber C, Countryman K, Fahrenbruch J, LaCount K, Cornwall M (1992) Measurement of reactive vasodilatation during cold gel pack application to non- traumatized ankles. PhysTher 72:294-299

21. Driscoll D, Appiah-Yeboah A, Salib P, Rupert D (2007) Merging qualitative and quantitative data in mixed methods research: how to and why not'. Ecol Environ Anthropol 3:19-28

22. Sale JEM, Lohfeld LH, Brazil K (2002) Revisiting the quantitative-qualitative debate: implications for mixed-methods research. Qual Quant 36:43-53

23. Abdullah M, Ahmed H, Mohammed A, Ali M. The self-concept dimensions of the employed and unemployed women and its relationship with the level of stress and family adjustment in the Dakhlia Governorate.2014;

24. Braun V, Clarke V (2006) Usingthematicanalysisinpsychology. Qual Res Psychol 3:77-101.1 
25. Demir Y (2012): Non-pharmacological therapies in pain management-

Current Issues and Opinions, Dr. Gabor Racz (Ed.), ISBN: 978-953-307-813-7,

InTech. Available at: http://www.intechopen.com/books/pain-man-agement-

current-issues-and-opinions/non-harmacologicaltherapies-in-pain-

management.

\section{Publisher's Note}

Springer Nature remains neutral with regard to jurisdictional claims in published maps and institutional affiliations.

Submit your manuscript to a SpringerOpen ${ }^{\odot}$ journal and benefit from:

- Convenient online submission

- Rigorous peer review

- Open access: articles freely available online

- High visibility within the field

- Retaining the copyright to your article

Submit your next manuscript at $\boldsymbol{\nabla}$ springeropen.com 